\title{
Ámbitos de regeneración, intervención y comunicación artísticas: De la Castellana al Madrid Río
}

\author{
Areas of artistic regeneration, intervention and communica- \\ tion: from La Castellana to Madrid-Río
}

\author{
MARÍA Dolores ARroyo FernándeZ \\ Universidad Rey Juan Carlos \\ mdarroyo@ccinf.ucm.es
}

Recibido: $16 / 06 / 2019$

Aceptado: 21/09/2019

\section{Resumen}

En este estudio se realiza un recorrido general de enlace de dos puntos estratégicos que actualmente forman el perfil de Madrid: eje Castellana-Recoletos-Prado y los distintos ámbitos y circuitos que lo conectan con el Madrid Río. Desde un eje de arte privilegiado, plataforma de eventos artísticos y celebraciones de todo tipo, de espacio tradicional de turismo, a lo largo del tiempo se han ido constituyendo trayectos de arte hacia las periferias. El resultado ha sido una siempre recobrada convivencia entre escultura, arquitectura, espacio urbano y naturaleza.

Palabras clave

Arte Público, Regeneración Urbana, Madrid-Río, Distritos Culturales.

\begin{abstract}
In this study, a general route linking two strategic points that currently form the profile of Madrid is carried out: the Castellana-Recoletos-Prado axis and the different areas and circuits that connect it with the Madrid Río. From a privileged art axis, a platform for artistic events and celebrations of all kinds, from a traditional tourism space, art journeys have been established over time to the peripheries. The result has been an always recovered coexistence between sculpture / architecture / urban space and nature.
\end{abstract}

Keywords

Public Art, Urban Regeneration, Madrid-Río, Cultural Districts. 
Referencia normalizada: ARROYO FERNÁNDEZ, MARÍA DOLORES (2019): “Ámbitos de regeneración, intervención, ycomunicación artística: de la Castellana al Madrid-Río". En Arte y Ciudad. Revista de Investigación, no 15-16 (2019), págs. 51-82. Madrid. Grupo de Investigación Arte, Arquitectura y Comunicación en la Ciudad Contemporánea, Universidad Complutense de Madrid.

Sumario: 1. Introducción. 2. Eje Castellana, Recoletos, Prado. 2.1. De Plaza Castilla a Plaza Colón. 2.2. Ámbito Plaza Colón a Atocha. 3.3. Manifestaciones artísticas temporales a lo largo del eje Castellana, Recoletos, Prado. 3. Conexiones al Madrid Río. 3.1. Desde Plaza Colón a Moncloa. 3.2. Desde Atocha a Arganzuela. 3.3. Madrid Río: Barrios conectados. 4. Bibliografía.

\section{Introducción ${ }^{1}$.}

En este estudio se realiza un recorrido general de enlace de dos puntos estratégicos que actualmente forman el perfil de Madrid: el eje Castellana, Recoletos, Prado y los distintos ámbitos y circuitos que lo conectan con el Madrid Río. Desde un eje de arte privilegiado, plataforma de eventos artísticos y celebraciones de todo tipo, de espacio tradicional de turismo, a lo largo del tiempo se han ido constituyendo trayectos de arte hacia las periferias. El resultado ha sido una siempre recobrada convivencia entre escultura, arquitectura, espacio urbano y naturaleza. Por esta razón se contemplan varios hitos de reactivación y regeneración de estos espacios ciudadanos, siguiendo un itinerario desde el centro emblemático a los barrios colindantes con el río Manzanares. Monumentos, escultura pública, acciones, exhibiciones e intervenciones artísticas en el espacio urbano, se han incrementado dando lugar a una nueva imagen plástica y documental de Madrid. Una ciudad en donde se superponen o conviven pasado y presente, formas y estilos históricos diferentes, priorizando el nivel de comunicación y participación ciudadana.

\footnotetext{
${ }^{1}$ El presente artículo se presentó en una primera versión en la publicación Barrios Artísticos y Distritos Culturales. Nuevos espacios para la creatividad y la revitalización urbana. Miguel Ángel Chaves - Jesús Pedro Lorente (eds.), Icono 14 Editorial, Madrid, 2016, como parte de los resultados del proyecto de investigación sobre barrios artísticos (HAR2012-38899-C02-02) del que es continuación el proyecto Arte, Arquitectura y Patrimonio en los procesos de construcción de la imagen de los nuevos enclaves culturales (PGC2018-094351-B-C42).
} 


\section{Eje Castellana, Recoletos, Prado.}

La línea trazada en este apartado recoge dos importantes extremos: desde la Plaza Castilla a la Plaza del Emperador Carlos V (Atocha). Ámbito extenso y favorecido que cruza la ciudad, en él se concentra la mayoría de los museos públicos a los cuales se han sumado otros centros o entidades culturales de distinta naturaleza. Es además espacio de exhibiciones artísticas temporales, de celebraciones y eventos heterogéneos de matiz político-cultural-recreativo.

\subsection{Plaza Castilla a Plaza Colón.}

En la Plaza Castilla confluyen hoy distintos edificios que conforman uno de los perfiles más modernos de Madrid (Fig.1). Se han agregado a lo largo del tiempo distintas edificaciones y monumentos, se han abierto al público espacios ajardinados, se ha puesto en marcha proyectos culturales y sociales con la intención de regenerar la zona, de modernizarla y adaptarla a las nuevas exigencias urbanísticas, de transporte y movilidad. El Depósito del Canal y su entorno, el Monumento a José Calvo Sotelo, la Puerta de Castilla, la Puerta Europa, el Obelisco Calatrava, han ido imponiendo progresivamente su estética y funcionalidad al ciudadano. La manifiesta diferencia de cada edificio atiende a las necesidades y a la estilística de la época de su construcción, pero también exige en el presente una comprensión de su sentido en el contexto de la plaza.

En primer lugar, el cambio de uso del Depósito del Canal como Fundación Cultural comenzó en el $2005^{2}$, siendo el mayor de sus objetivos el servicio a la sociedad "Desde su sede, junto a la Plaza de Castilla de Madrid, la Fundación Canal se dirige a la sociedad en defensa del agua, como bien cultural, fuente de vida y como recurso escaso y vulnerable, en el fomento de su gestión sostenible", como así se describe en su web3 ${ }^{3}$, con el fin de que los ciudadanos tomen conciencia de la trascendencia social, económica y ambiental de este recurso. Para ello su acción se concentra en actividades de interés general: exposiciones, conferencias, conciertos, foros de debate, publicaciones, abarcando todos los campos del pensamiento, la cultura, el arte, la historia, y las ciencias naturales y sociales. Con la Fundación Canal, un edificio de arqueología industrial de primeros del siglo XX se convierte en espacio cultural moderno (Casas, 2005).

\footnotetext{
${ }^{2}$ En el 150 aniversario de la creación de Canal de Isabel II, se constituyó la Fundación Canal.

${ }^{3}$ http://www.fundacioncanal.com/ ; http://www.cyii.es/ente/historia_6.html
} 
Consta de aulas, salas de exposiciones, auditorio para conciertos, conferencias, debates; asimismo integra un gran parque sobre la cubierta del Cuarto Depósito. Muestras como Guerreros de Xi'an en 2004-2005 a la actual, 2015-16, dedicada a Cleopatra y la fascinación de Egipto; pero ante todo, presta atención especial a todas "las manifestaciones artísticas que nacen de la relación del ser humano con su entorno". El abanico de disciplinas y lenguajes es, por tanto, muy abierto, aunque sin desviarse de su fin último: hacer que el visitante reflexione acerca de los diferentes aspectos que inciden sobre la conservación del medio ambiente y, en particular, sobre el valor del agua.

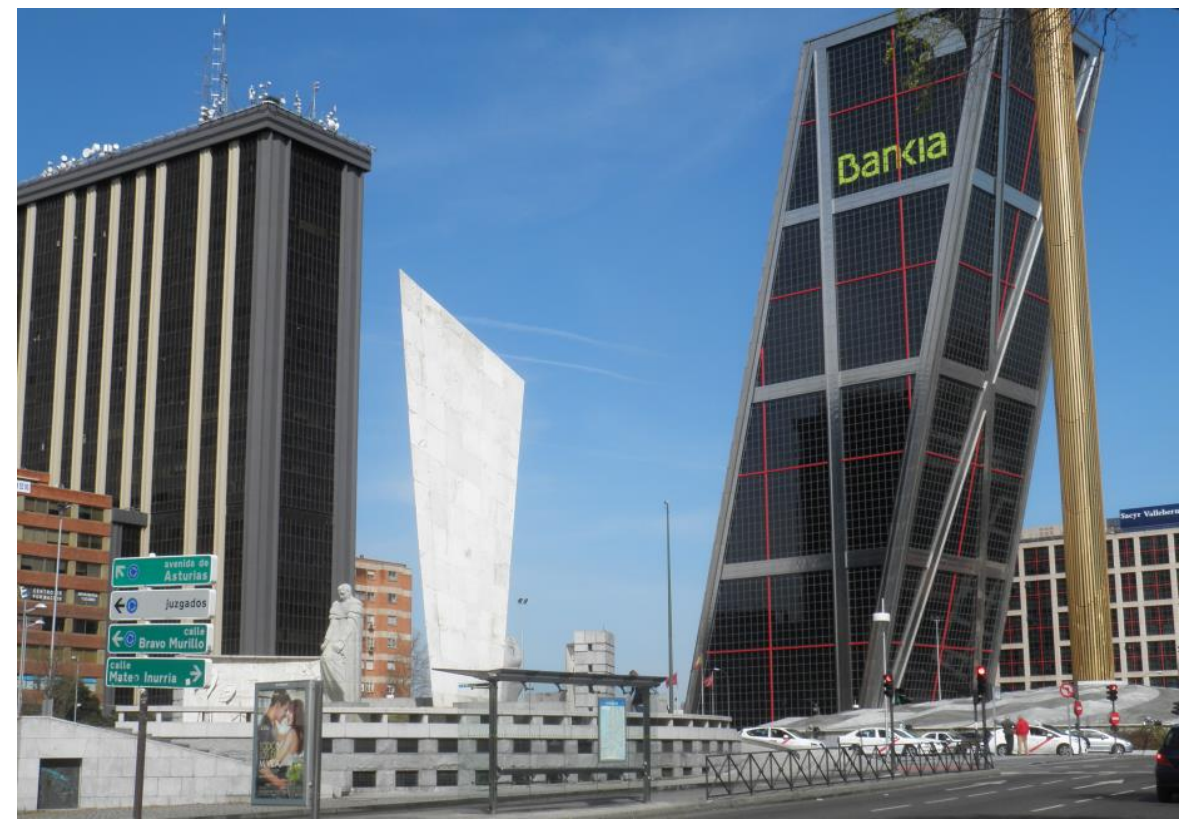

Fig. 1 - Plaza Castilla, Madrid, junio 2012. Fuente: M.D. Arroyo

En un lado de la Plaza Castilla, al final de la que se llamó Avda. Generalísimo, se levanta desde 1960 el Monumento a José Calvo Sotelo, inaugurado el 13 de julio de 1960, en el 24 aniversario de su asesinato (Brown, 2014). Este político ${ }^{4}$ (1893-1936) fue considerado «protomártir de la Cruzada» al ser ase-

\footnotetext{
${ }^{4}$ José Calvo Sotelo había recibido una calle Paseo de José Calvo Sotelo, con que se denominó el histórico Paseo de Recoletos. Su nombre original fue recuperado en 1981 siendo alcalde de Madrid Enrique Tierno Galván.
} 
sinado poco antes del inicio de la Guerra Civil. La obra fue encargada por el régimen franquista al arquitecto Manuel Manzano Monís y Mancebo ${ }^{5}$ (Sevilla, 1913 - Madrid, 1997) y al escultor Carlos Ferreira de la Torre (Valdemoro, Madrid, 1914), que en 1970 se trasladó a Tenerife y allí vivió hasta su muerte en 1990. De material constructivo hormigón armado, en su estética se combina el monumentalismo constructivo retórico con la vanguardia artística de los años sesenta. La perspectiva frontal del monumento, mirando a la Castellana, crea con respecto a la inclinación de las posteriores Torres Kío un perfecto eje de simetría. Varias controversias y opiniones se han vertido sobre dicho monumento, sobre todo en relación con la inconveniencia, o no, de que éste siga figurando en la plaza. Ejemplo de este debate son peticiones como la firmada en el País por Carlos Pla y Abogados, al considerar que "ni la relevancia artística del monumento, ni su escasa originalidad lo hará pasar a la historia ni su simbolismo" (Pla, 1991).

En 1979 se incorpora la llamada Torre Castilla, construida por la promotora Filasa para una cooperativa de jueces; un edificio que estéticamente difería de las ya existentes construcciones del juzgado. Tampoco conectaba, ni formal ni visualmente, con el resto de inmuebles que configuraban el espacio de la plaza Castilla, llamado "espacio maldito" en el blog de Farina (Farina, 2008). Con más de 70 metros la Torre de Castilla destacó por su altura, aunque otras construcciones la han superado. Puerta de Europa, o Torres Kío ${ }^{6},(1989-1996)$, dos torres ${ }^{7}$ acristaladas e inclinadas expresamente hacia el mismo lugar, simétricas con respecto al eje Castellana. De una manera simbólica, la idea de la Puerta de Europa sigue la tradición de sellar el área de la ciudad con puertas urbanas. Se convirtió entonces en uno de los edificios más altos de Madrid, y su visibilidad desde cualquier punto ha marcado, y sigue marcando, el skype de la capital.

La Torre I fue adquirida por la Caja Madrid (Bankia) y Torre II por Realia. Los arquitectos, Philip Johnson ${ }^{8}$ (Cleveland, 1906) y John Burgee (Chicago,

\footnotetext{
5 También escritor, se le otorgó el "Premio Europeo a la Reconstrucción de la Ciudad" por su trabajo de recuperación del casco antiguo y del conjunto amurallado de Fuenterrabía (Guipúzcoa).

${ }^{6}$ Porque fueron encargo de Kuwait Investments Office.

${ }^{7}$ Altura $114,7 \mathrm{~m}$ de altura y casi 30 plantas

${ }^{8}$ Discípulo de Mies van der Rohe, en 1979 recibe el primer premio Pritzker de la historia: el Nóbel de la arquitectura.
} 
1933), socios desde 1967 a 1991, idearon una forma plástica basada en una gráfica que tenía una inclinación de $15^{\circ}$ del ruso Alexander Rodchenko (18911956). Su idea era romper con el concepto de diseño lineal. Johnson en su visita a las torres en 1996, afirmó: "...Hay que acabar con el ángulo recto si no nos queremos morir del aburrimiento...", “...Los arquitectos nos podemos concentrar ahora en la misión de hacer las formas de los edificios que mejoren al hombre..." ${ }^{\prime 9}$. La Puerta de Europa, con su entonces extraña estética de estructura metálica de acero y hormigón, de juego de diagonales, verticales y horizontales, de brillo intenso del metal, de vidrio oscuro, de cuadrícula roja, se integra al resto de los edificios de la plaza y al trajín y el paseo diario. En la vida cotidiana del ciudadano, se interfieren también las esculturas públicas, como la obra de José María Cruz Novillo (Cuenca, 1936) instalada en 1996 en la puerta de entrada de la Torre II.

A las Torres Kío se sumaron las Cuatro Torres Business Area (CTBA) ${ }^{10}$, iniciadas en el 2004 sobre terrenos del complejo deportivo del Real Madrid, y terminadas en el 2009. Al aplicarse el emblema "hacer más ciudad", con la prolongación de la Castellana hacia el norte, hacia la ciudad del futuro los PAUs, el skyline de Madrid ha cambiado para siempre y un nuevo logo identifica la imagen de marca de esta ciudad.

Con motivo del 300 aniversario de fundación Caja Madrid (1702-2002), esta entidad encargó al arquitecto y escultor Santiago Calatrava (Valencia, 1951) el diseño de un monumento que sería donado a la Villa de Madrid. El Obelisco de la Caja u Obelisco de Calatrava ocupó el centro de la Plaza de Castilla, después de ser desmantelada la fuente existente. Inspirado en la Columna del Infinito (1938) del escultor rumano Constantin Brâncuşi (1876-1957), el proyecto de 92 metros $^{11}$, consta de un fuste metálico cilíndrico sobre pivotes de hormigón, superficie de lamas y movimiento ascensional a manera de onda ${ }^{12}$. Las obras se iniciaron en julio del 2008 y fue inaugurado oficialmente el 23 de di-

\footnotetext{
${ }^{9}$ http://es.wikiarquitectura.com/index.php/Torres_Kio

${ }^{10}$ Las Cuatro Torres, la gran postal de Madrid del siglo XXI telemadrid, actualizado el 18 dic. 2009. https://www.youtube.com/watch?v=XTaX-hA3f1o

${ }^{11} \mathrm{El}$ proyecto iba a tener $120 \mathrm{~m}$ de altura, pero se rebajó a 92 metros dada la complejidad de su construcción, por su magnitud y su peso.

12 "Obelisco de Calatrava en movimiento día y noche".

https://www.youtube.com/watch?v=Z6m6zPoUcR8
} 
ciembre de 2009 por S.M. El Rey. Sin embargo, el coste elevado de conservación y mantenimiento, su limpieza y vigilancia, el mal funcionamiento del mecanismo móvil, han resultado un lastre a muchos efectos (Sanz, 2014). Deyan Sudjic en Arquitectura del poder (Sudjic, 2007) plantea ese endiosamiento de los arquitectos puestos al servicio de los poderosos, y con múltiples ejemplos se refiere a los excesos, desde las construcciones de la época de Hitler al Guggenheim de Bilbao. El caso de Calatrava podría entrar en el libro como un ejemplo más de su estudio.

Si la Plaza Castilla ha ido adquiriendo la apariencia actual, espacio amplio y abierto cubierto de torres de distintas épocas y estilos y una actividad cultural significativa a través de la Fundación Canal, otro centro neurálgico anterior a destacar es el Puente de Eduardo Dato en cuyos bajos se asienta el Museo de Arte Público de La Castellana. Inaugurado oficialmente el 9 febrero 1979, su restauración integral se realizó en 2001-2002, (Fig.2).

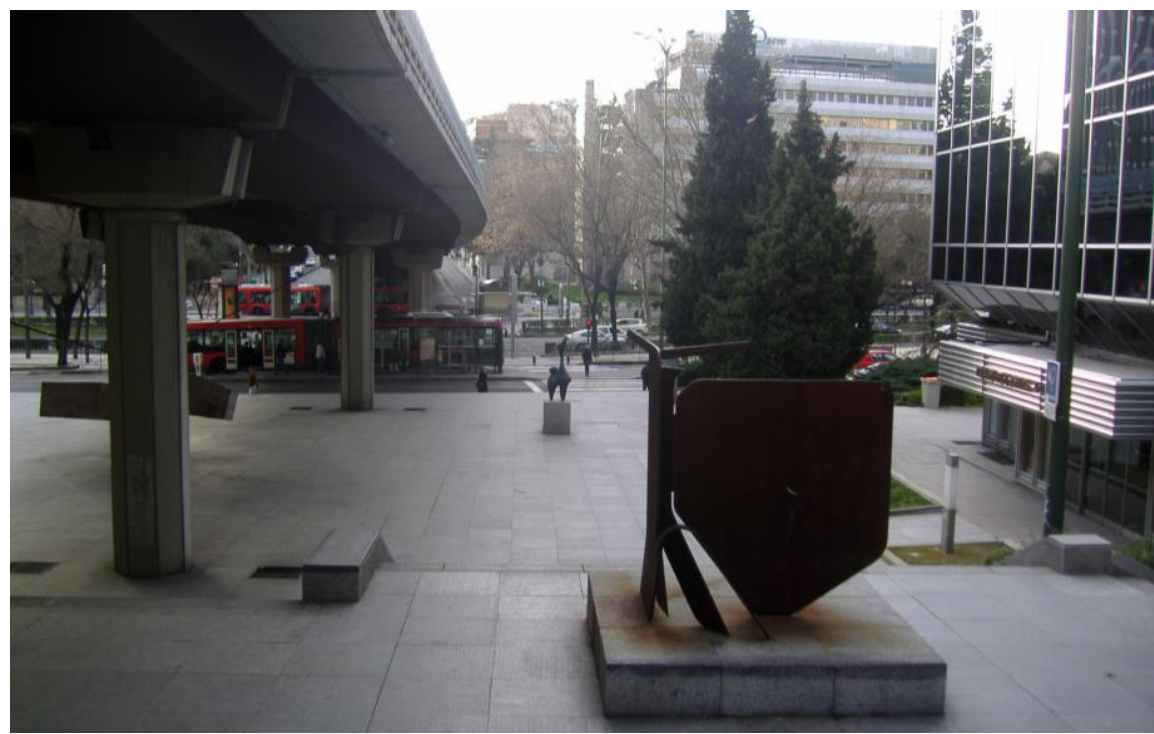

Fig. 2 - Museo Arte Público, vista general con obra de Palazuelo: Proyecto para monumento IV B, 1978, acero corten, febrero de 2008. Fuente: M.D. Arroyo.

Este museo es un ejemplo de colaboración de artistas e ingenieros, y pionero en Madrid de un espíritu que aúna lo urbano y la obra de arte: exhibición de forma permanente de esculturas en espacio urbano. El proyecto cumple su objetivo, no solo funcional y urbanístico sino también estético y pedagógico. 
En su andar el ciudadano se aproxima al arte moderno, pues existe una intencionada unidad y sentido en el recorrido expositivo de las obras escultóricas (de Alberto Sánchez, Julio González, Miró, Chillida, Chirino, Rivera, Sempere, Palazuelo etc.) que acompañan al peatón. Este mismo espíritu del pionero Museo de Arte Público (Arroyo, 2012), que ha supuesto la regeneración de una zona de Madrid en la Castellana, va a imponerse en proyectos sucesivos en este mismo $\mathrm{u}$ otros ámbitos urbanos de Madrid. Muchas son también las intervenciones que reinterpretan o interfieren en los monumentos ya existentes, como el diálogo establecido entre la escultura perteneciente a la vanguardia clásica española del Paseo de la Castellana (Museo de Arte Público) con intervenciones modernas del certamen "Madrid Abierto" (Arroyo, 2012).

\section{2. Ámbito Plaza Colón a Atocha.}

La siguiente parada de la Castellana hacia Atocha es el ámbito de la Plaza de Colón (Fig.3). Uno de los lugares en donde se concentra un cúmulo de edificaciones, escultura monumental, centro cultural municipal y edificios públicos ya veteranos (Biblioteca Nacional, Museo Arqueológico). El monumento a Colón, que fue desplazado durante la remodelación de la plaza, vuelve a ocupar el lugar original en el centro. La escultura se levantó para enaltecer el matrimonio de don Alfonso XII con doña María de las Mercedes de Orleáns. Por iniciativa real, la estatua de 3 metros de altura fue realizada por el escultor Jerónimo Suñol (Barcelona, 1840- Madrid, 1902) en mármol blanco de Italia, sobre pedestal neogótico, florido y tallado en piedra por Arturo Mélida (Madrid, 1849-1902). Iniciada la construcción del monumento en 1881, se terminó en $1885^{13}$. Viste sayo y manto propios de su tiempo. En la mano derecha porta una bandera de Castilla, que apoya sobre un globo terráqueo, al tiempo que tiende la izquierda en ademán de oferta, y dirige su mirada al cielo (Salvador, 1990).

Con la modernización, ordenación y urbanización de la plaza y su entorno, y por exigencias de tráfico, se proyectó, en el lugar que ocupaba la antigua Casa de la Moneda, un espacio ajardinado ${ }^{14}$ para uso y disfrute de pueblo de

\footnotetext{
${ }^{13}$ Debido a la muerte de don Alfonso XII, no pudo inaugurarse en la fecha señalada para el 6 de enero de 1886. El 12 de octubre de 1892 se hizo entrega del Monumento a Colón al Ayuntamiento de Madrid.

${ }^{14}$ Arquitecto Manuel Herrero Palacios, director del Departamento de Parques, Jardines y Estética Urbana, siendo alcalde Carlos Arias Navarro.
} 
Madrid, un aparcamiento subterráneo y el Centro Cultural de Villa -desde febrero de 2008 llamado Fernán Gómez Centro Cultural de la Villa-, cuya historia se detalla en su página web ${ }^{15}$. Situado en el circuito de arte más importante de la ciudad, el centro municipal consta de tres espacios culturales: la Sala Guirau (Teatro), la Sala Jardiel Poncela y la Sala de Exposiciones. Hoy ha desaparecido la fuente alargada original, que servía de límite con la vía de la plaza. Una vez decidido el carácter conmemorativo del proyecto, se homenajeaba dicha plaza a las hazañas del Descubrimiento ${ }^{16}$. La narración del viaje y las profecías que lo anticiparon se ilustra tanto en los relieves e inscripciones de los muros exteriores del Centro Cultural de la Villa como en las tres enormes esculturas públicas, situadas en el límite con la calle Serrano, Monumento al Descubrimiento de América, obra del pintor y escultor Joaquín Vaquero Turcios (Madrid, 1933 - Santander, 2010) e inaugurada el 15 de mayo de 1977 (Fernández, 1982: 178-183).

Fig. 3 - Plaza de Colón, febrero de 2010. Fuente: M.D. Arroyo

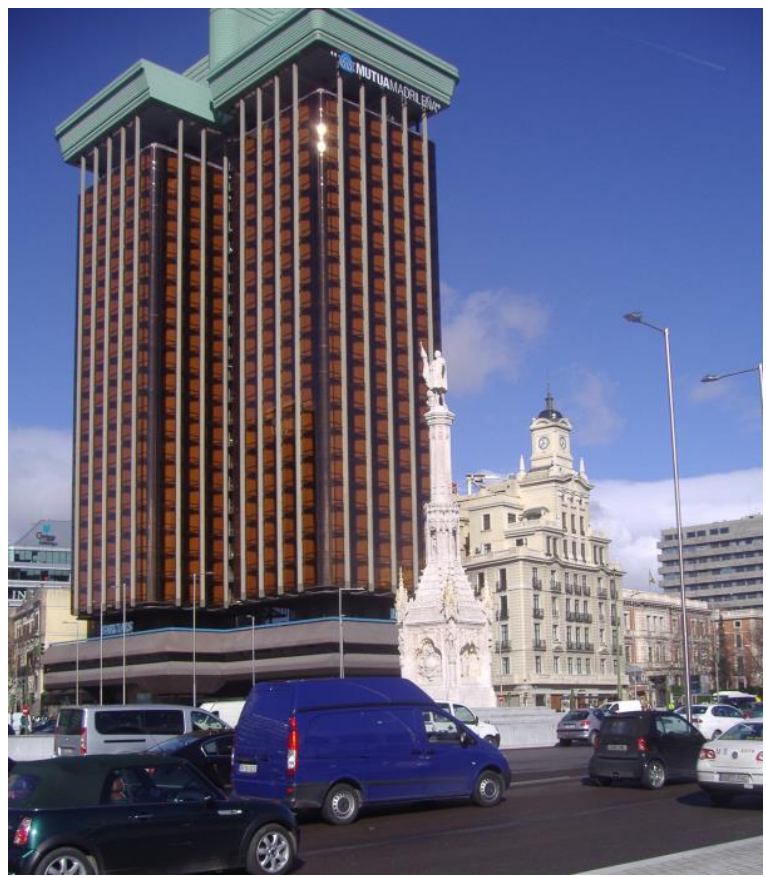

\footnotetext{
${ }^{15}$ http://teatrofernangomez.esmadrid.com/;

http://teatrofernangomez.esmadrid.com/informacion/historia/

16 No a la Hispanidad, ya que ésta era una consecuencia del Descubrimiento.
} 
Los dos rascacielos gemelos ubicados en la Plaza de Colón: las Torres de Colón ${ }^{17}$ con sus 116 metros de altitud y sus 23 plantas, cambiaron el panorama y la estética de la plaza desde que se levantaron en 1976. Sus autores: el arquitecto madrileño Antonio Lamela y los ingenieros Leonardo Fernández Troyano, Javier Manterola y Carlos Fernández Casado, idearon dos grandes pilares unidos en la cima por una plataforma de la que cuelgan las dos torres $^{18}$ y fachadas cubiertas por cristal de color granate. Se corona con un elemento verde añadido posteriormente: "el enchufe". La construcción original de "arriba abajo" asombró a los madrileños en los años setenta por este peculiar método de construcción (Bitagoras.com, 2013).

Los Paseos de Recoletos y del Prado han sido motivo de múltiples proyectos de reformas, muchos muy polémicos, pero que, en definitiva, han sido intentos de adaptar y conformar un espacio cultural y museístico de calidad en sintonía con otras capitales europeas, como la de Berlín. En la XII Semana de la Arquitectura 2015 del COAM: La Isla de los Museos vs Eje PradoRecoletos $^{19}$, se debatió dentro de un área urbana, las cualidades urbanísticas de Madrid y Berlín en cuanto a sus dotaciones museísticas y culturales. Se diferenció, en la mesa redonda organizada a propósito, las dimensiones y población de ambas capitales; más extensa en Berlín y más compacta y densificada en el centro histórico de Madrid. El Paseo Recoletos (Fig. 4) que continúa a Cibeles se ha convertido en espacio para el desarrollo de actividades muy diversas desde las culturales a recreativas y políticas; entorno muchas veces regenerado a tenor de las prioridades y necesidades de cada momento.

El llamado Paseo del Arte va tomando más cuerpo con el traslado de la sede de la Fundación cultural Mapfre a un palacio en el Paseo de Recoletos en otoño de 2008. El edificio de cuatro plantas y semisótano, fue construido en 1884 por el arquitecto Agustín Ortiz de Villajos (Quintanar de la Orden, 1829 - Madrid, 1902) para la duquesa de Medina de las Torres. La oferta cultural de la Fundación se presenta hoy en tres espacios: el citado de Recoletos, dedicada a exposi-

\footnotetext{
${ }^{17}$ Fue sede de Rumasa, y su nombre se cambió por el de Torres Jerez, por la ciudad andaluza originaria de dicha empresa. Hoy alberga oficinas de diferentes empresas y comercios en las plantas bajas. ${ }^{18}$ https://es.wikipedia.org/wiki/Panorama_urbano_de_Madrid

19 "La Isla de los Museos vs Eje Prado-Recoletos". Semana de la Arquitectura 2015, COAM. 02/10/2015. http://www.coam.org/es/actualidad/agenda/agenda-coam/mesa-redonda-coloquiola-isla-museos-vs-eje-prado-recoletos
} 
ciones fotográficas en la cercana calle Bárbara de Braganza, mientras se mantiene la Sala Azca en la Avda. General Perón para muestras de distinta índole. Después de una fundamental revisión del arte español de finales del siglo XIX hasta la Guerra Civil, ha derivado a una programación más internacional iniciada con Degas, procesos de creación, que es la desarrollada en la actualidad ${ }^{20}$. La compañía de seguros posee centro de exposiciones, centro de documentación, salas de conferencias, edición de arte e historia, ofrece becas y desarrolla importante acción social. Participa con más de 350 fotografías de su Colección en el Google Art Project, para la difusión de sus fondos.

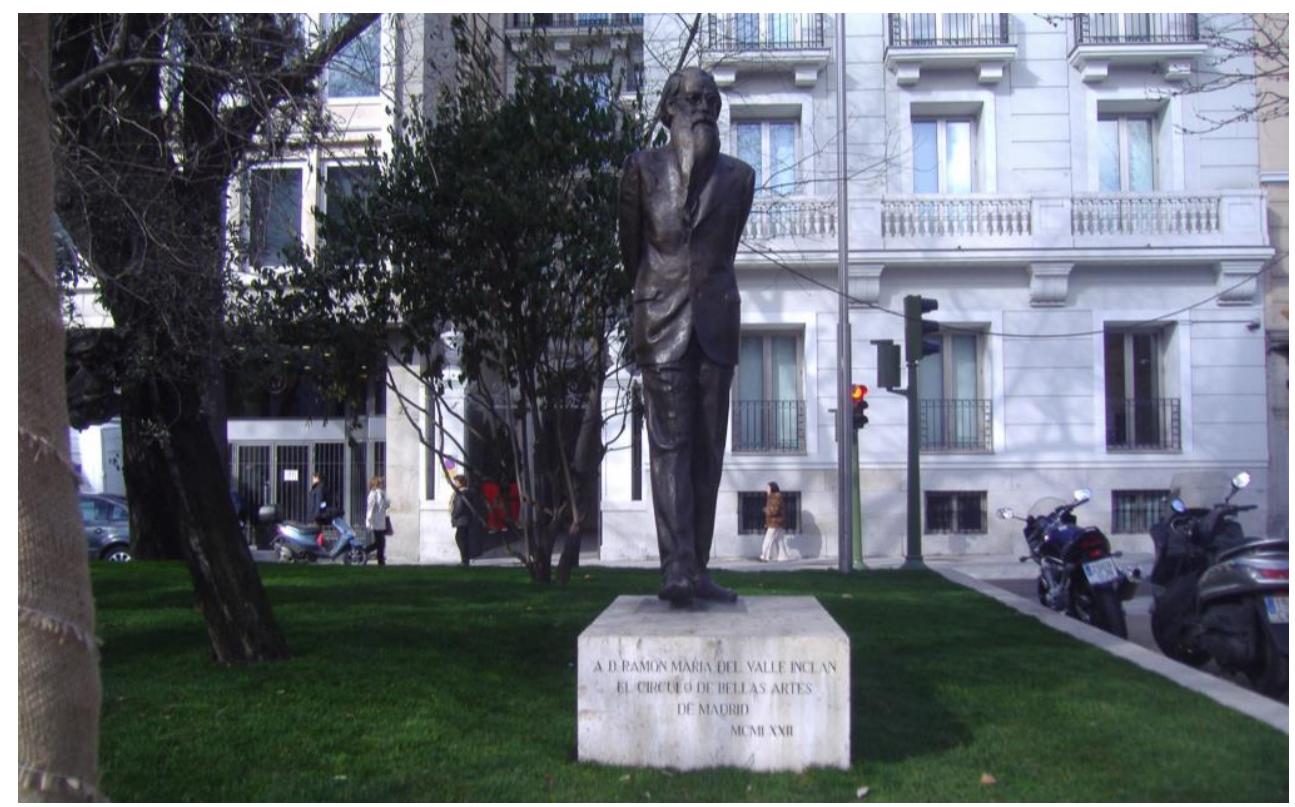

Fig. 4. Estatua de Valle Inclán en el Paseo de Recoletos, febrero 2010. Fuente: M.D. Arroyo

En la Plaza de Cibeles se halla el Palacio de Linares ${ }^{21}$, hoy la Casa de América $^{22}$, una de las instituciones más activas en su programación de eventos de

\footnotetext{
${ }^{20}$ Programación de exposiciones de pintura, escultura y dibujo centrada en el estudio del período que abarca del tercio final del siglo XIX hasta después del fin de la II Guerra Mundial. http://www.fundacionmapfre.org/fundacion/es_es/cultura-historia/

${ }^{21}$ Se mandó construir 1877 por los Marqueses de Linares (José María Murga y Reolid y su esposa Raimunda Osorio y Ortega). Las obras finalizaron en 1900. Arquitectura de Carlos Colubí, Adolf Ombrecht y Manuel Aníbal Álvarez y motivos decorativos del exterior (ángeles, jarrones y escudos nobiliarios) fueron obra del escultor Jerónimo Suñol.
} 
distinta índole (actos culturales, exposiciones, conferencias o ciclos cinematográficos y literarios), con el objetivo de fomentar un mejor conocimiento entre los pueblos iberoamericanos y España. El edificio se integra al ámbito de la calle a través de la zona de jardín en su entrada por la Castellana esquina Marqués del Duero. Enfrente, cruzando la calle Alcalá, el más joven incorporado es el Centro de Arte, Palacio de Cibeles, en el que fue Palacio de Correos, obra de Antonio Palacios y Otamenti (1876-1945), construido en 1907-1919. La recuperación de un edificio para centro cultural municipal con una oferta muy amplia y variada, así como la descripción y funcionalidad de sus espacios, se detallan en su web ${ }^{23}$. La planta principal es punto de información cultural sobre Madrid, una exposición permanente sobre la historia del Palacio de Cibeles, su restauración y transformación actual ${ }^{24}$ (2005) en sede del Ayuntamiento de Madrid y en gran centro cultural. En las distintas plantas se da acogida a proyectos artísticos sobre cultura urbana y propuestas de reflexión en torno a la ciudad actual, la futura y sobre sus habitantes, como la celebración de la I Feria Internacional Ciudad Creativa, 2013. Fundamental es la línea expositiva sobre mecenazgo al servicio del arte, cuyo fin es abrir las colecciones privadas al gran público: Legado Casa de Alba, Helga de Alvear Masaveu Peterson, Colección Abelló, Kandinsky. La Galería de Cristal alberga la feria anual Art Madrid, que este año, 2016, tuvo a Carmen Calvo como artista invitada. CentroCentro Cibeles se ha consolidado como un centro cultural con espacios para el diseño, creación sonora, para la fotografía, arquitectura y el edificio, símbolo de la ciudad, ofrece una vista privilegiada desde su Mirador situado en la gran torre del palacio hacia las distintas calles que confluyen en la plaza de Cibeles.

Pionera en España en gestión privada de fondos públicos, la Fundación Colección Thyssen-Bornemisza ${ }^{25}$ se creó en 1988, abriendo el Museo en octubre de $1992^{26}$ en el que fue el Palacio de Villahermosa, obra de Antonio López

\footnotetext{
${ }^{22} \mathrm{http}: / / \mathrm{www}$. casamerica.es/

${ }^{23} \mathrm{http}$ ///www.centrocentro.org/centro/espacios

${ }^{24}$ Estudio de arquitectura de Francisco Rodríguez Partearroyo y asociados, especialistas en este terreno.

${ }^{25}$ http://www.museothyssen.org/thyssen/historia

${ }^{26}$ Durante el verano de 1992, se lleva a cabo el traslado de 800 obras a España desde la antigua sede de la Colección en Villa Favorita en Lugano.
} 
Aguado (Sangüesa, 1764-1831) de 1805, diseñado y remodelado para museo por Rafael Moneo (Tudela, 1937). El incremento de la colección ${ }^{27}$, la variedad y riqueza de exposiciones temporales, programas didácticos y actividades de todo tipo se ha incrementado de tal modo que ha pasado a ser, dentro del Triángulo del Arte y frente al Museo del Prado, uno de los lugares obligados de cita cultural para todos los públicos. La disposición de distintos ámbitos de reunión, además del espacio ajardinado de la entrada, permite que se abra al exterior como una zona de encuentro y de esparcimiento público. Este proyecto se halla acorde con la tendencia general de diseño de ampliación para estos espacios que aglomeran gran número de visitantes. Al adquirir dos inmuebles adyacentes al Palacio de Villahermosa, el Museo Tyssen ha podido mejorar los programas complementarios a la colección permanente y a la vez combinar dos estilos: la fachada posterior palaciega con el edificio moderno.

Al famoso Triángulo del Arte en el Paseo del Prado, formado por el Museo del Prado, el Museo Tyssen y el Museo Nacional Centro de Arte Reina Sofía, se incorpora en el 2008 Caixaforum Madrid, frente al Real Jardín Botánico. El edificio, que fue la Central Eléctrica del Mediodía que abastecía de energía al sector sur del casco antiguo y se empezó a construir en 1900 a nombre del empresario José Batlle, es uno de los pocos ejemplos de edificio industrial de la zona. Este es, por tanto, otro ejemplo de rehabilitación, reforma y remodelación de un edificio antiguo, propiedad de la ONCE, para su adecuación a proyectos culturales, educativos y sociales (Hemeroteca ABC, 2001) en este caso por parte de la Fundación la Caixa. La reforma fue llevada a cabo entre 2003-2008 por el estudio de arquitectura Herzog \& De Meuron ${ }^{28}$.

El edificio conserva su fachada original de ladrillo visto, de acuerdo al Plan General de Madrid de 1997. A través de una escalera de caracol se accede a las distintas plantas en donde se encuentran biblioteca-mediateca, auditorio, talleres, salas de exposiciones ${ }^{29}$. Delante de la fachada que da al Paseo del Prado se ha ganado, con la demolición de una vieja gasolinera, un espacio que hace de pequeña plaza acotada en uno de sus muros por un tapiz vegetal. Este jardín vertical fue diseñado en 2007 por el botánico especialista en plan-

\footnotetext{
${ }^{27}$ En 2004 se incorporó como préstamo a largo plazo la Colección Carmen Thyssen-Bornemisza.

${ }^{28} \mathrm{https}$ ///www.herzogdemeuron.com/index/focus/444-expo-milano-focus/introduction.html

${ }^{29}$ Exposiciones que antes se realizaban en la Sala de Exposiciones de la calle Serrano.
} 
tas del sotobosque tropical Patrick Blanc (París, 1953) ${ }^{30}$. Este espacio exterior, al aire libre, es lugar de encuentro y también expositivo. Allí se expusieron temporalmente, entre otras, las Meninas de Manolo Valdés (2009) en una muestra de "Arte en la Calle" (Fig.5), y también en el espacio exterior de Caixaforum, el monumental elefante de Mikel Barceló en 2010 o el Pensador y los Burgueses de Calais de Rodin en 2009 (Fig.6). Estas exhibiciones son otra manera de acercar el arte al ciudadano a pie de calle y una invitación a penetrar en el interior del edificio y a participar de su variada programación.

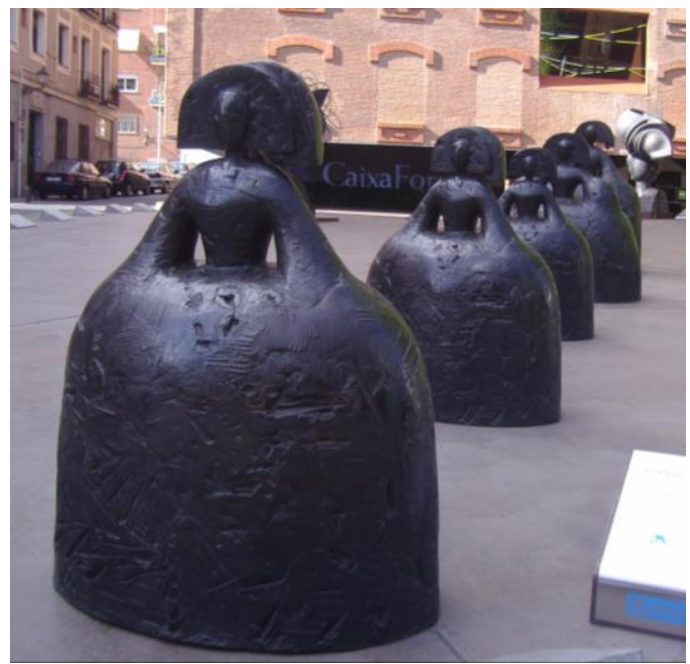

Fig. 5. Meninas Manolo Valdés, “Arte en la Calle" Caixaforum, oct. 2009. Fuente: M.D. Arroyo

Fig. 6 - Burgueses de Calais de Rodin en Caixaforum, marzo de 2009. Fuente: M.D. Arroyo

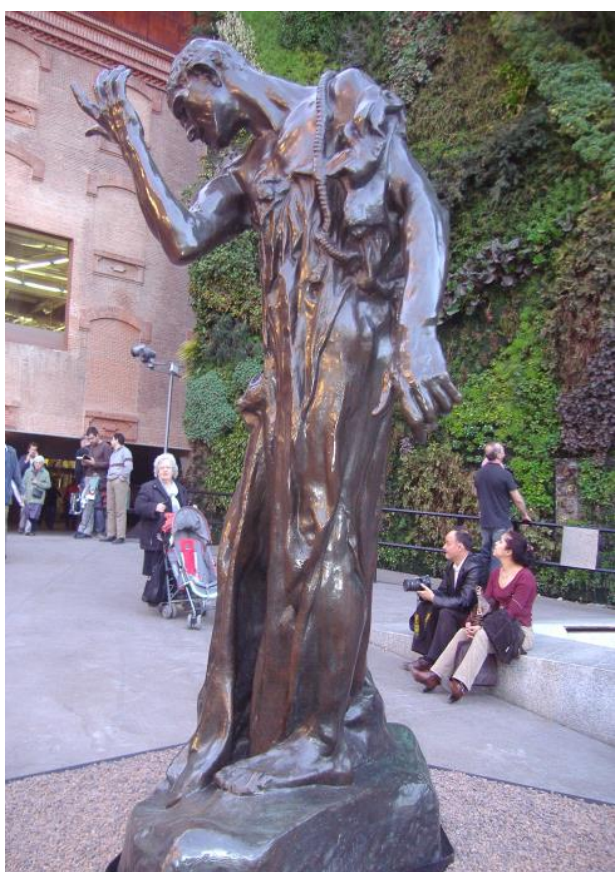

El Museo Nacional Centro de Arte Reina Sofía (MNCARS), antes Centro de Arte Reina Sofía (Arroyo, 1990: 153-157), en el vértice sur del Triángulo del Arte, fue inaugurado en $1992^{31}$ en el edificio que fue antiguo Hospital General de

\footnotetext{
${ }^{30}$ Trabaja para el Centre National de la Recherche Scientifique (CNRS), se caracteriza por crear jardines verticales en forma de muro vegetal. http://www.murvegetalpatrickblanc.com/

31 Con fondos artísticos procedentes del antiguo MEAC (Museo Español de Arte Contemporáneo). En la actualidad, es un organismo autónomo dependiente del Ministerio de Educación, Cultura y Deporte. En 2013 se aprobó el estatuto propio del museo.
} 
Madrid, de estilo neoclásico del siglo XVIII. El hoy llamado edificio Sabatinizi2 fue completado con la ampliación del edificio Nouvel, inaugurado en el 2005. En un entorno privilegiado (Calle Santa Isabel. Ronda de Atocha y esquina plaza del Emperador Carlos V), su amplia programación ${ }^{33}$ de arte contemporáneo, más los centros y galerías de arte que han proliferado a su alrededor, cercano al Barrio de Las Letras, hacen de este lugar una área de excepción.

Atocha, como testigo de los atentados terroristas, ha ido transformando su aspecto al incorporar obras homenaje a estos dramáticos acontecimientos. El Monumento homenaje a las víctimas del 11-M, del estudio de arquitectura FAM ${ }^{34}$, fue inaugurado por los Reyes Don Juan Carlos I y por Doña Sofía el 11 de marzo de 2007, en el tercer aniversario de los atentados. El monolito, de 11 metros y diámetro de 9,5 metros, se alza delante de la estación de tren de Atocha y consta de dos partes: una exterior acristalada visible desde la plaza del Emperador Carlos V y otra interior a la que se accede desde la estación. Posteriormente se sumó a este monumento el conjunto escultórico en bronce formado por dos enormes cabezas de una misma niña, una despierta y otra dormida, El día y la noche ${ }^{35}$ de Antonio López (Tomelloso, 1936). Siendo un homenaje a las víctimas del 11-M, para el artista el simbolismo de la escultura no refleja el miedo y la angustia sino la esperanza e inocencia, algo reconfortante para los viajeros. Colocadas las dos cabezas, en julio 2008 (García, 2008), en la planta baja de la estación, junto a los andenes, el conjunto se trasladó al exterior en noviembre de 2010 debido a la remodelación de la estación de Atocha y su entorno (Fotonoticia, 2010).

\subsection{Manifestaciones artísticas temporales a lo largo del eje Castellana- Recoletos-Prado}

No habría espacio aquí para mencionar la cantidad de manifestaciones, muestras y eventos que periódicamente se han desarrollado a lo largo de esta línea excepcional que une Plaza Castilla y Atocha. De forma ocasional, este espacio de la ciudad se ha convertido en ámbito de reflexión y algunos de sus

\footnotetext{
32 Diseño de José de Hermosilla y continuado después por Francesco Sabatini.

${ }^{33} \mathrm{http}: / / w w w . m u s e o r e i n a s o f i a . e s /$

${ }^{34}$ El concurso se falló el 30 de noviembre de 2004. Este estudio creado en 2002 desarrolla una acción interdisciplinar de proyectos de arquitectura y urbanismo.

${ }^{35}$ Retrato de una de las nietas del artista cuando aún tenía pocos meses.
} 
edificios más emblemáticos han sido sometidos a una relectura, a recreaciones visuales simbólicas y también críticas. La intervención de Sans Façon ${ }^{36}$ en el Depósito de Agua de la Plaza de Castilla, durante el evento Madrid Abierto 2004 (Fig.7), convierte un edificio utilitario en una "escultura" al dotarlo de una ornamentación ajena a su sentido simplemente funcional. De esta forma, este depósito de hormigón que se ha convertido en plateado, pasa a ser foco de las miradas de la gente. Su fin es que los paseantes se fijen y aprecien esa estructura que es emblema de la Plaza y un ejemplo del progreso hidráulico de la ciudad. "Por un período de tiempo, el depósito elevado se convierte en un acontecimiento. Mientras que anteriormente formaba parte de nuestra observación diaria, adquirirá una nueva existencia en la memoria y la imaginación una vez pasada la intervención" ${ }^{37}$.

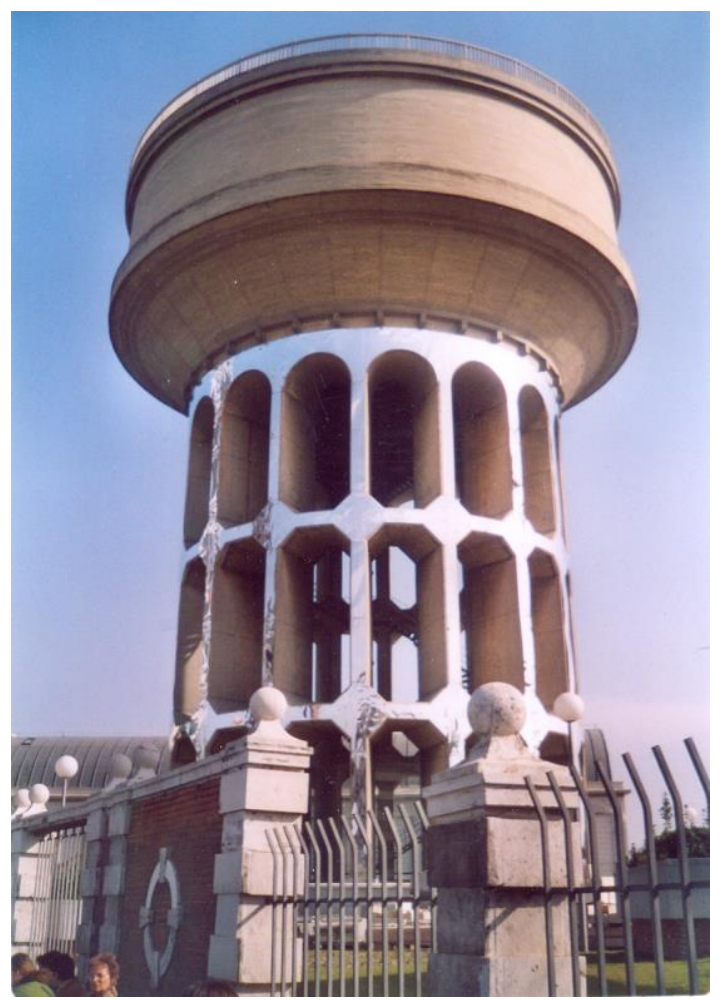

Fig. 7 - Intervención de Sans Façon en el Depósito de Agua del Canal, Plaza Castilla, Madrid Abierto 2004. Fuente: M.D. Arroyo

\footnotetext{
36 Sans façon: colaboración práctica entre el artista (Tristan Surtees) y el arquitecto (Charles Blanc). http://www.sansfacon.org/

${ }^{37} \mathrm{http}$ //www.madridabierto.com/intervenciones-artisticas/2004/sans-facon.html
} 
Esta intervención de Sans Façon es una de las primeras manifestaciones de lo que a partir de ahora será bastante habitual en las programaciones que convierten temporalmente la calle y su arquitectura en museo al aire libre. Un nuevo ejemplo, entre otros, la muestra escultórica titulada Forma y Color de la artista griega Sophie Vari en el Paseo de la Castellana (Fig.8); organizada por la Junta municipal de Chamberi y el Ayuntamiento de Madrid, entre el 4 de abril y 4 de septiembre de 2011. Y, específicamente, referente a la relación de las nuevas obras de arte con los edificios y el espacio histórico existente, se ha intentado establecer diálogos de distinta naturaleza, como el generado entre la escultura de vanguardia clásica del museo de Arte Público de la Castellana y los distintos proyectos del "Madrid Abierto".

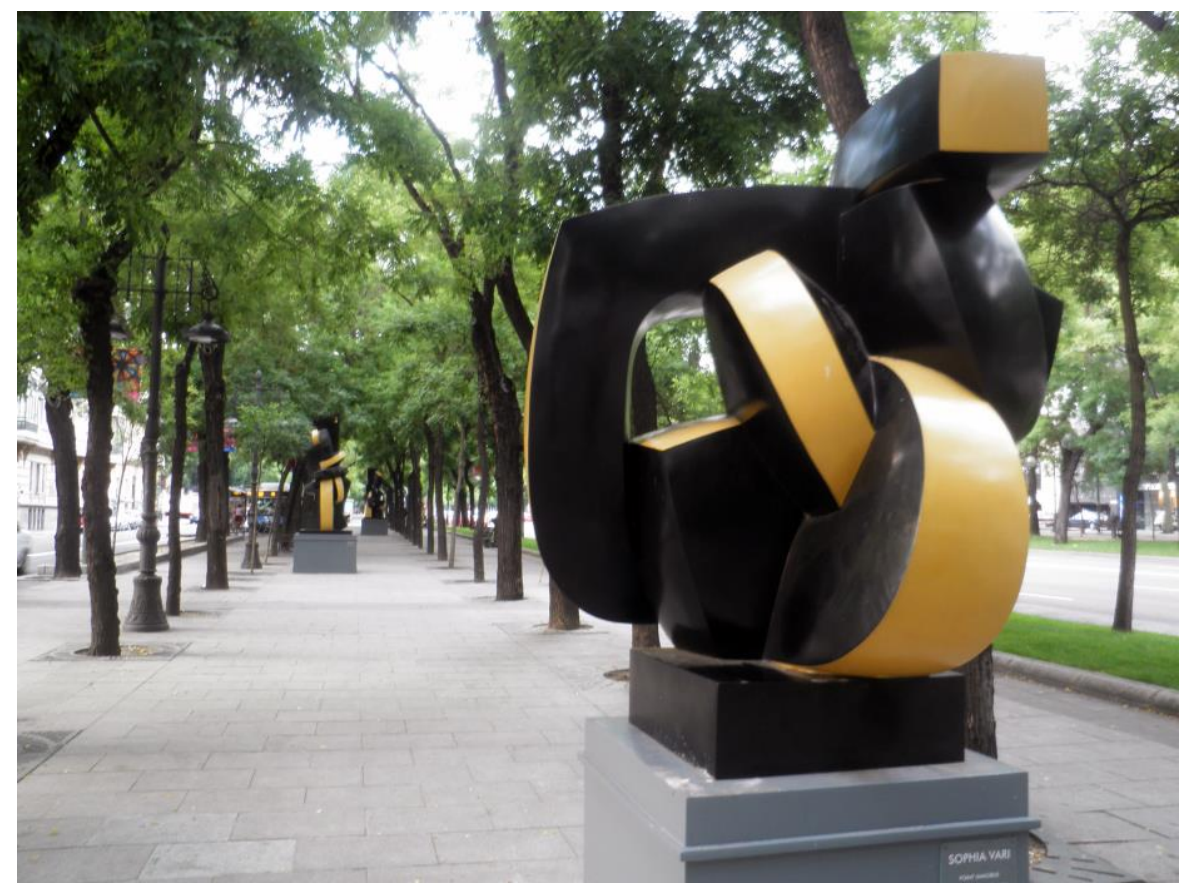

Fig. 8. Exposición en el Paseo de la Castellana de Sophia Vari, junio de 2011 Fuente: M.D. Arroyo

En el circuito Recoletos, Cibeles, hasta Atocha, no solo se concentran los edificios más emblemáticos de la ciudad, sino que en estos mismos espacios se han desarrollado proyectos de artistas de forma puntual y exposiciones temporales. Ello reactiva el arte, lo acerca a la calle y sugiere estímulos al ciu- 
dadano para la reflexión. Es significativo el nombrado "Madrid Abierto" en sus distintas ediciones (Arroyo, 2012: 87-98). Sirvan de ejemplo House Madrid $^{38}$, trabajo del alemán Wolfgang Weileder o los carteles y banderolas de Maider López, ambas obras ubicadas en el Paseo Recoletos, durante el "Madrid Abierto", 2004. Dos intervenciones, una basada en la construcción y deconstrucción simultáneas de un muro (casa) y la otra, una realización pictórica integrada en el espacio urbano en forma de carteles publicitarios. Mientras tanto, la intervención de José Dávila en la fachada de la Casa de América, en la Plaza de Cibeles, titulada Mirador Nómada y presentada en "Madrid Abierto" 2005, tenía como objetivo utilizar dicha fachada como punto estratégico para observar las calles más representativas de Madrid, un lugar desde donde normalmente no se tiene acceso. Su propuesta es por tanto inversa pues aquí los andamios que suben a la plataforma que sirve de balcón no ocultan el edificio, como sería lo tradicional, sino que posibilitan una visión panorámica de la Plaza de Cibeles, el Paseo de Recoletos y Calle de Alcalá. Otra intervención artística es OFF, de Dan Perjovschi en el mobiliario urbano del Paseo Prado y Paseo Castellana durante el "Madrid abierto", 2007. Los llamados muppis ${ }^{39}$ no publicitaban nada sino que mostraban dibujos sintéticos llenos de humor, comentarios a la situación política, social, cultural y artística del lugar. Se establecía así un diálogo entre éstas condiciones y las circunstancias propias experimentadas como artista rumano.

Todo el eje Castellana-Recoletos-Prado es lugar para las reivindicaciones y manifestaciones políticas, socio-culturales (día mundial de la cultura, música, coros, cabalgatas); espacio para eventos artísticos en donde el ciudadano toma la calle. Se ha pasado de un lugar frecuentado solo por la élite del siglo XVIII a una progresiva proliferación de eventos masivos y de espectáculos. Desde que en los años setenta, la ciudad se convierte en lugar de recepción de ideas o discursos artísticos y el público participa, incluso él mismo es generador de la obra, la consecuencia directa ha sido que el arte y la cultura se convierten en una gran fiesta. Sea eventos como las esculturas expuestas en el Homenaje en el V centenario: Cristóbal Gabarrón: Silencios de Cristóbal Colón en el Paseo del Prado, 2006, la muestra de esculturas del artista Pop Robert In-

\footnotetext{
${ }^{38} \mathrm{http}: / /$ www.house-projects.com/

${ }^{39} \mathrm{http}: / /$ madridabierto.com/intervenciones-artisticas/2007/dan-perjovschi.html
} 
diana en el Paseo del Prado, 2006; o la performance contra la violencia de género y malos tratos de Ouka Leele: Revive Cibeles, 10 septiembre 2006, para conmemorar los 20 años de la puesta en escena alrededor de la Cibeles del mito de Atalanta e Hipómenes (1987). Más intervenciones como el Palacio Encantado (Fig.9) en el Palacio de Linares, durante el "Madrid Abierto" 2004, en que su autora, Diana Larrea, partía de los mitos del cine para crear esa atmósfera de misterio, como la que nos envolvió Hitchcock en su film Los Pájaros.

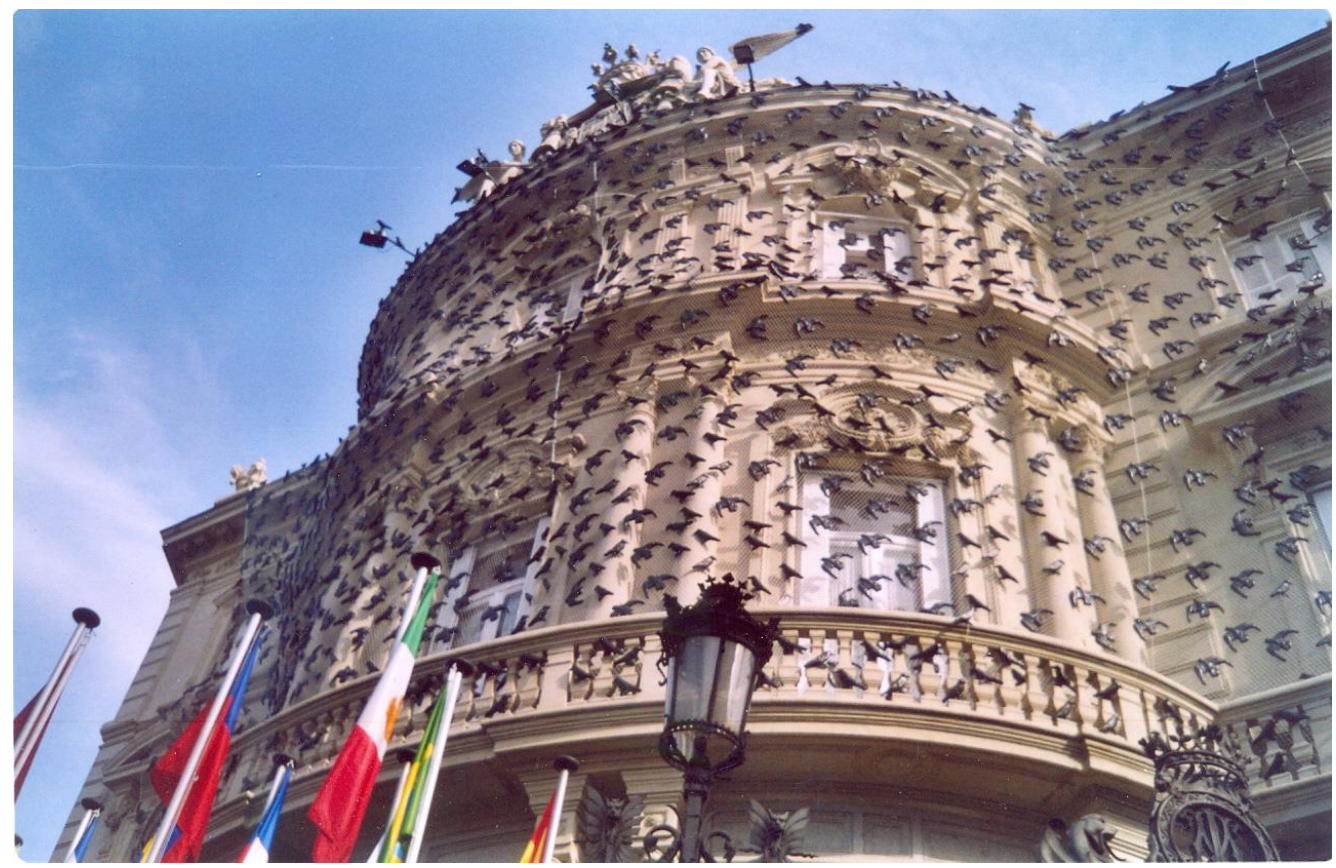

Fig. 9 - Palacio Encantado, Intervención en el Palacio de Linares de Diana Larrea Madrid Abierto 2004, febrero, 2004. Fuente: M.D. Arroyo

En la Plaza de las Letras se encuentra desde 2007 el Centro Cultural Municipal Medialab-Prado ${ }^{40}$, concebido como un laboratorio ciudadano de producción, investigación y difusión de proyectos culturales ${ }^{41}$. Partiendo de un edificio industrial de hormigón armado de los años veinte, Serranía Belga, los arqui-

\footnotetext{
${ }^{40}$ Iniciado en el 2000 en el Centro Cultural Conde Duque, en el 2002 pasa a denominarse MediaLabMadrid. En septiembre de 2007 se traslada a la Plaza de las Letras, cerca del Paseo del Prado, en los bajos del edificio de la Serranía Belga.
}

${ }^{41} \mathrm{http}: / /$ medialab-prado.es/article/que_es 
tectos María Langarita y Víctor Navarro ${ }^{42}$ llevaron a cabo su rehabilitación y adaptación. Edificio cercano a Caixaforum y en el comienzo del Barrio de las Letras, entre sus objetivos se haya el incentivar el trabajo colaborativo desde diferentes perfiles, niveles y grados de implicación. Entre sus actividades de interés, por lo que supone del uso y ocupación del espacio exterior de la plaza, están convocatorias como "Fachada digital" del programa europeo Connecting Cities. En 2013 la propuesta temática de experimentación consistió en conectar entre sí ciudades, barrios y personas. Cabe destacar el trabajo de Pedro Valbuena: Entramado - Plaza de Luz, una instalación urbana en la Plaza de las Letras, proyecciones de luz sobre espacios físicos, un ejemplo de uso de la llamada escultura aumentada, que combina la realidad física y virtual.

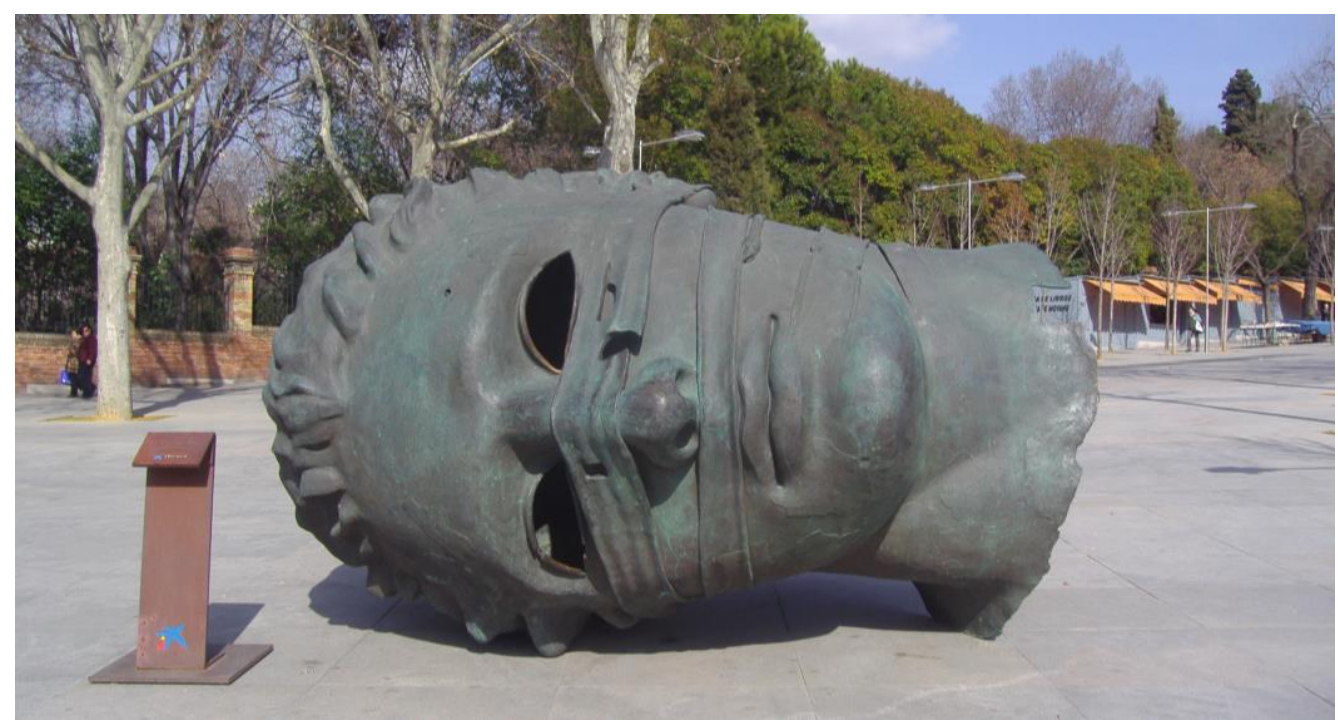

Fig. 10. Mitoraj en Cuesta Moyano, exposición Caixaforum, febrero 2008. Fuente: M.D. Arroyo

Ya en el ámbito de Atocha, la Plaza del Emperador Carlos V se vio sorprendida, durante la celebración de la "Noche en Blanco" de 2009, por un Burro gigante obra de Fernando Sánchez Castillo. La escultura de 17 metros de alto y 9,5 metros de ancho, destacó por su sentido irónico, como así es el mor-

\footnotetext{
${ }^{42}$ http://www.langarita-navarro.com/. Ha recibido el premio de la XII Bienal Española de Arquitectura y Urbanismo, el Premio COAM 2013 y el Premio Sacyr a la Innovación 2014.
} 
daz estilo de su autor al referirse a monumentos, símbolos y anécdotas españolas. Sobresalen las ya señaladas celebraciones del "Madrid Abierto", "Noche en Blanco", o muestras temporales en la calle, como la dedicada a las esculturas de Igor Mitoraj, que ocuparon en febrero de 2008 el Paseo del Prado, Plaza de Atocha, adentrándose en la Cuesta Moyano en dirección al Retiro, como parte del programa de la Caixa de "Arte en la Calle" (Fig.10).

\section{Conexiones al Madrid Río.}

Ya explicado lo anterior, se pueden establecer dos grandes conexiones hacia el Madrid Río: desde la Plaza Colón por los Bulevares ${ }^{43}$ y la que sale de Atocha bajando hacia el sur por las Rondas.

\subsection{Desde Plaza Colón a Moncloa.}

Una de las características "gordas" de Fernando Botero, La Mujer con espejo, colocada bajo una base de flores ${ }^{44}$ frente a las Torres de la Plaza de Colón, nos adentra desde la calle Génova y, por los bulevares, hacia el distrito de Argüelles. Esta escultura se ha sumado al recorrido históricamente existente de monumentos escultóricos inaugurados el 5 de junio de 1902, como homenaje a la mayoría de edad de Alfonso XIII. El trazado finalizaba con el Monumento a Argüelles en la confluencia de las calles Alberto Aguilera, Princesa y Marqués de Urquijo, aunque después de varios traslados y recolocaciones la última ubicación tuvo lugar en marzo 2011, en la confluencia entre el Paseo Pintor Rosales y calle Ferraz junto al Templo de Debod. Se subió a un nuevo pedestal mucho más elevado para evitar deterioros a la estatua, (Arroyo, 2011: 275-287).

Como puede verse, las esculturas monumentales se colocan en la vía pública y se incorporan a la vida diaria del ciudadano. Se impone una estética, una historia y unos valores, pero también pueden perder su sentido y las referencias comunicativas con el ciudadano cuando por razones urbanísticas éstas

\footnotetext{
${ }^{43}$ Denominación genérica de las cinco vías sucesivas que forman parte del primer anillo de circunvalación en el arco norte del casco antiguo de Madrid: calles de Marqués de Urquijo, Alberto Aguilera, Carranza, Sagasta y Génova.

44 Escultura de bronce fundido. 82,5 × $353 \times 125 \mathrm{~cm}$, fue regalada por el escultor al Ayuntamiento de Madrid después de la buena acogida que tuvo la exposición titulada "Botero en Madrid", formada por 21 piezas y que se celebró durante la primavera de 1994 a lo largo del Paseo de Recoletos. Javier Górriz. http://www.fotomadrid.com/ver/521
} 
obras son trasladadas de su emplazamiento originario. A veces prevalece mantener un significado en el contexto en que se ubica, como el diálogo establecido entre las tres esculturas (Monumento Víctimas de la Aviación Militar, Monumento a los Héroes del Plus-Ultra, Mirada del Horizonte II) ${ }^{45}$ que actualmente están instaladas en la Plaza de la Moncloa (Fig.11), frente al que fue Ministerio del Aire (Arroyo, 2012: 229-238).

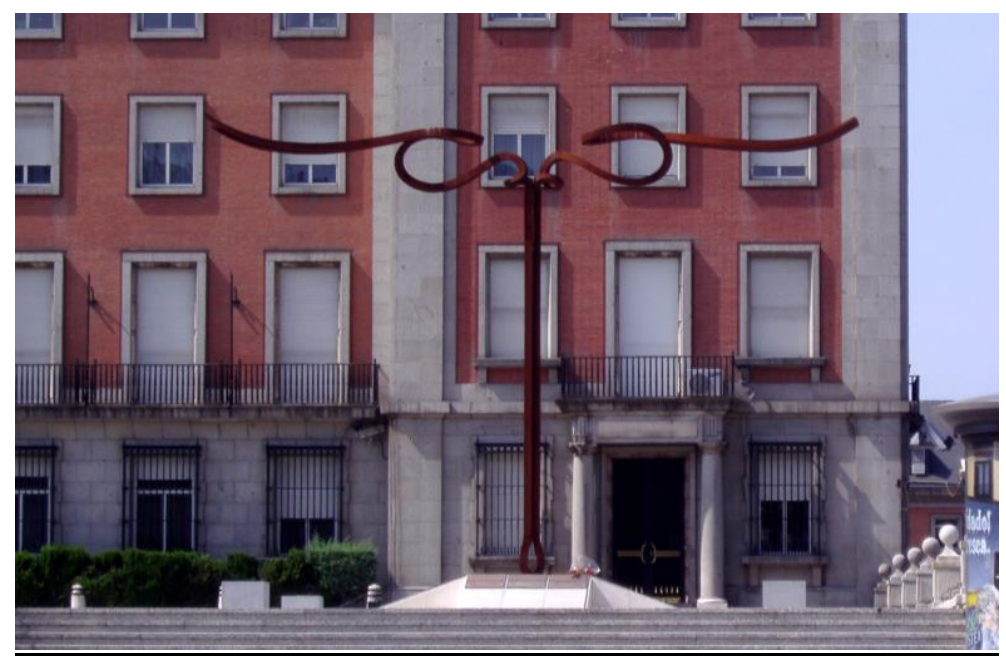

Fig. 11. Martín Chirino, Mirada del Horizonte II, 2006, en la Plaza Moncloa. Fuente: M.D. Arroyo

En los laterales del recorrido por los bulevares, varios ámbitos de interés se han sumado a este trayecto cultural que lleva hacia el Madrid Río: Centro Cultural Conde Duque ${ }^{46}$, que contiene el Museo de Arte Contemporáneo y el Estudio de Gómez de la Serna; programa una intensa actividad cultural desde exposiciones, conferencias, cine, conciertos de música y danza, además de albergar en su seno la Hemeroteca nacional, archivo histórico y bibliotecas. El Real Cuartel de Guardias del Corps de 1717 fue restaurado y rehabilitado para nuevos usos en los años ochenta del siglo $X X$. En distintas fases se ha ido conformando y adaptando el aspecto que tiene hoy, siendo uno de los centros de cultura y de ocio más importantes del barrio Universidad en distrito Centro, al lado de Argüelles. Los proyectos de exposiciones sobre arte español

\footnotetext{
${ }^{45}$ Manuel Delgado Bracquenbury: Monumento a las Víctimas de la aviación militar (1918-1995). Rafael Saénz (escultor), Luis Gutiérrez Soto (arquitecto) Monumento a los Héroes (1951/ 1956) del Plus-Ultra. Martín Chirino: Mirada del Horizonte II (2006).

${ }^{46} \mathrm{http}: / /$ www.condeduquemadrid.es/
} 
contemporáneo ${ }^{47}$ han destacado especialmente debido a la iniciativa de sus diferentes directores, el primero Luis Caruncho. Pero fue a partir del año 2000, cuando Juan Carrete Parrondo, el cuarto director, abrió una línea de trabajo muy distinta y novedosa: la creación del taller de arte digital Medialab, que ocupó desde entonces gran parte del espacio y de la programación del centro cultural, hasta 2007 en que se traslada a la Plaza de las Letras. Sobre la relevancia y repercusión de esta iniciativa se pronunciaba Juan Carrete: “Hoy lo importante es crear redes de comunicación entre creadores. (...) Más que de artistas, se habla de activistas, porque tienen una finalidad no sólo multidisciplinar sino interdisciplinar. (...) lo que se potencia es el trabajo colaborativo". (Rubio, 2008), aconsejando a otros centros de arte contemporáneo a ser dinámicos y a que se fijaran más en los procesos creativos que en las obras mismas.

En la calle Amaniel, cerca del Centro Cultural Conde Duque se encuentra desde el 2010 el Museo ABC del Dibujo y la Ilustración. Incorporado a esta red de entusiastas iniciativas culturales de Madrid, el edificio actual es el resultado de la rehabilitación de de la que fue en 1891 la primera fábrica de Cervezas Mahou en Madrid, obra del arquitecto José López Salaberry (18581927). Consta de una colección ABC del dibujo y la ilustración y da cabida a la promoción y exposición de este tipo de manifestación artística. El Museo $\mathrm{ABC}$ "tiene como principal objetivo conservar, estudiar y difundir la Colección $\mathrm{ABC}$, así como diseñar y desarrollar un exhaustivo programa de actividades artísticas" ${ }^{48}$. Su configuración y adaptación de espacios para nuevo uso es innovadora y fue realizada por el estudio de arquitectos Aranguren \& Gallegos $^{49}$, que respetó el entorno y el edificio existente (Fig.12).

Donde confluyen los bulevares (Marqués de Urquijo) y el Paseo de Rosales $^{50}$ se encuentra desde 1939 el Retrato del pintor Eduardo Rosales (1835-1873), estatua en mármol blanco de Mateo Inurria (1867-1924) realizada 1922. Primero se colocó en el Paseo Recoletos y desde 1939 se encuentra en el paseo que inmortaliza el nombre del pintor. Esta pieza escultórica sigue la línea

\footnotetext{
${ }^{47}$ http://www.condeduquemadrid.es/info/conde-duque-madrid/

${ }^{48} \mathrm{http}: / /$ museo.abc.es/

${ }^{49} \mathrm{http}: / /$ www.arangurengallegos.com/ag/

${ }^{50}$ Paseo de Rosales se abrió con el ensanche de Argüelles en 1875.
} 
desde Colón y la Mujer con espejo de Botero al inicio del recorrido de los bulevares para desembocar en nuevos recintos regenerados que se van acercando al Madrid Río. Por un lado, se llega a la Casa de Campo por el Teleférico de Rosales cruzando por el aire el río Manzanares; asimismo desde la Escuela de Cerámica en el Parque del Oeste se llega al recinto de las dos Ermitas de San Antonio de la Florida, al Parque de la Bombilla y a las urbanizaciones cruzando el río por el Puente de la Princesa. Por otro lado, el Paseo de Rosales dirige sus pasos al Templo de Debod en la Montaña del Príncipe Pío, un verdadero mirador a la Casa de Campo (Arroyo, 2015).

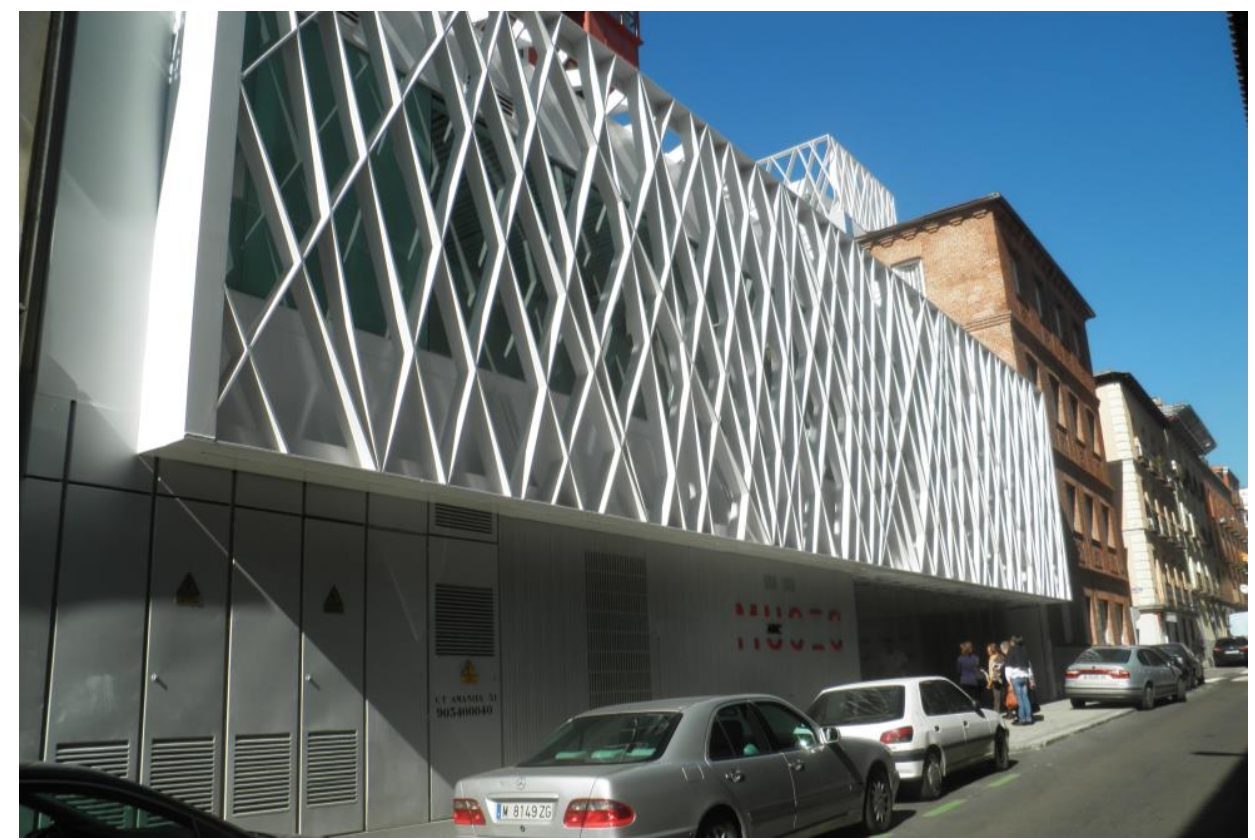

Fig. 12. Museo ABC de la Ilustración, Madrid, febrero 2011. Fuente: M.D. Arroyo

Desde el tramo inicial del río Manzanares, entre Puente de los Franceses y el Puente del Rey, al que se llega desde el Parque del Oeste, el camino a lo largo del Madrid Río permite el acceso a zonas ahora ajardinadas. Al contrario que las ciudades alemanas que tienen déficit de plazas, de lugares de encuentro, y en las que domina el verde del paisaje natural, “En España, las ciudades tienen densidades de locura. Eso provoca necesidad de tocar verde", pero el jardín debe ser siempre sostenible, afirma Peter Latz (Zabalbeascoa, 2008: 24). 


\subsection{Desde Atocha a Arganzuela}

La línea de unión de la Plaza de Carlos V hacia el Sur sigue la dirección a través de las Rondas ${ }^{51}$ hasta Arganzuela, separándose ésta de la traza irregular del Centro histórico. Desde allí enlaza más allá del río Manzanares con los barrios de Carabanchel y Usera. La historia pasada y la más reciente ha ido conformado todo este perfil urbano y ha convertido viejos edificios fabriles o de usos industriales en modernos centros artísticos. Las famosas Rondas constituyen hoy los caminos del arte, que hasta su llegada al ámbito del Madrid Río pasa por importantes centros de cultura, como La Casa Encendida o Tabacalera.

En la Ronda de Valencia, se halla La Casa Encendida ${ }^{52}$, que ocupa desde el 2002 el edificio que fue la casa de empeños del Monte de Piedad, diseñado por el arquitecto Fernando Arbós y Tremanti (Roma, 1844-Madrid, 1916) en 1878 e iniciada su construcción en 1911 en estilo italiano y neomudéjar. Hoy es un centro social y cultural que desarrolla múltiples actividades: exposiciones de arte, artes escénicas, cursos y talleres en el área de medio ambiente o solidaridad. La programación cultural ofrece artes escénicas, y da apoyo a jóvenes artistas. A él se suma el nuevo Teatro Circo Price con su variado programa de espectáculos, exposiciones y talleres. Inaugurado en 2007, la construcción se inició en 2002 según proyecto del arquitecto Mariano Bayón Álvarez (Madrid, 1942), utilizando las antiguas instalaciones de la fábrica de galletas Pacisa. Madrid se incorpora entonces a la red de ciudades que poseen ya circos estables como París, Bruselas, Munich Ámsterdam, Lisboa, Budapest, Londres, Viena, Manchester o Copenhague.

De la antigua entidad bancaria que fue el edificio de Casa Encendida, se pasa a la rehabilitada Antigua Fábrica de Tabacos, hoy Tabacalera, en la calle Embajadores. Construida entre 1780 y 1792 como Real Fábrica de Aguardientes y Naipes, pasó en 1809 a Fábrica de Tabacos y Rapé, manteniendo este uso hasta finales del siglo XX. En la actualidad, los grandes espacios están distri-

\footnotetext{
${ }^{51}$ Sucesión de cuatro vías que forman parte del primer anillo de circunvalación de Madrid en el arco sur del casco antiguo. Lo constituyen: la Ronda de Atocha que se inicia en la Plaza del Emperador Carlos V y confluye en la calle Valencia; Ronda de Valencia desde la Calle Valencia hasta Glorieta de Embajadores; Ronda de Toledo, desde Glorieta Embajadores hasta Glorieta de la Puerta de Toledo; Ronda de Segovia, desde Glorieta de la Puerta de Toledo hasta la calle de Segovia.

$52 \mathrm{http}: / / w w w . l a c a s a e n c e n d i d a . e s /$
} 
buidos en dos áreas: "Tabacalera. Promoción del Arte", gestionada desde 2003 por la Subdirección General de Promoción de las Bellas Artes del Ministerio, que desarrolla un programa permanente de exposiciones temporales y de actividades en torno a la fotografía, el arte contemporáneo y las artes visuales; y el resto ha sido cedido por el ministerio al Centro Social Autogestionado "La Tabacalera de Lavapiés"53. La sala principal para exhibiciones de gran formato, la Fragua, que en el 2013 se abrió con la exposición Chicago, fotografías de Raúl Urbina, está destinada a proyectos de artistas emergentes y site projects. Ámbito especial es el Espacio de arte urbano, que recupera el perímetro exterior de los muros para dar un nuevo uso convirtiéndolo en una galería de arte. Las primeras intervenciones en este espacio se han llevado a cabo con el proyecto "Muros Tabacalera" 54 .

La razonable coordinación puede evitar desajustes, como expresa Peter Lantz: "Del choque de teorías distintas deriva la fragmentación del paisaje actual" (Zabalbeascoa, 2008: 24), que considera un problema del paisaje actual en la recuperación de suelos industriales, en los que no debe esconderse su pasado.

\subsection{Madrid Río: Barrios conectados.}

Los dos ámbitos sobre los que se ha aludido que vienen del eje CastellanaRecoletos-Prado, desembocan en línea perpendicular en el río Manzanares, dejando de lado la conexión con el Madrid Río desde el Centro histórico más genuino: Palacio Real, Almudena, San Francisco El Grande. El alargado paraje del Madrid Río ya forma parte del perfil de la ciudad, espacio abierto, convertido en paisaje urbano, lo que antaño fueron los extrarradios de Madrid.

Un estudio previo (Arroyo, 2015: 153-170) que divide el proyecto del río en tramos, establece las conexiones entre los barrios de la rivera norte y sur de Manzanares. A través de puentes, antiguos o modernos, pasarelas, monumentos emblemáticos o centros culturales de distinto tipo, se ha insistido en su función de comunicación con el entorno a varios niveles: físico espacial (fijo o temporal), humano y significativo o conceptual. Se destacó en dicho

\footnotetext{
${ }^{53}$ http://www.mecd.gob.es/cultura-mecd/areas-cultura/promociondelarte/tabacalera/tabacalera -pres.html;jsessionid=D519FFD5A1F2031AA2D0049CD9599BB3

${ }^{54}$ http://www.murostabacalera.com/

http://www.murostabacalera.com/news/2014/5/15/intervenciones-muros-2014
} 
estudio la conjunción entre lo nuevo con lo antiguo, edificios históricos y modernos, la imagen del pasado y la actual con la implicación de los espacios intervenidos. Comprendiendo la actividad generada: artística y cultural, festiva y de ocio, incluso profesional, Madrid ha incrementado su perfil de ciudad y ha conformado una nueva estética del paisaje urbano. Todo ello no tiene más fin que adaptarse al siglo XXI y a las nuevas sociedades democráticas que demandan una ciudad más habitable, transitable, más cultura, conocimiento y respeto por el patrimonio. De esta manera se siguen los ejemplos de otras ciudades como Barcelona, Bilbao, Zaragoza, Gijón, entre otras, cuyas actuaciones se han centrado en el ámbito costero o en la rivera como eje central de conexión de barrios.

Algunos oficios, actividades festivas y de ocio continúan manteniéndose en el ahora Madrid Río, reemplazadas o modernizadas con el nuevo diseño de jardines y espacios para el ocio y deportes. El Puente del Rey, que forma conjunto monumental con la remodelada Puerta del Rey, sirve de enlace entre el Distrito Centro en el entorno de la rivera norte ( Puerta San Vicente, Estación del Príncipe Pío, Plaza de España, Jardín del Moro, Palacio Real y Catedral de la Almudena) y la Casa de Campo en la Latina.

En la sucesión de puentes a lo largo de la rivera hacia el suroeste, se ha buscado por estética y por funcionalidad la alternancia entre los ya existentes y los nuevos: el Puente de Segovia con sus remozados estanques, el Puente Oblicuo (1976) reconvertido para uso peatonal y ciclista, los tres brazos del Puente Verde en Y (2011), de acero, el Puente de San Isidro que lleva al Parque del mismo nombre y donde aún se mantienen sus típicas romerías. A la altura del Puente de Toledo y el Puente Monumental de Arganzuela o Puente de Perraut ${ }^{55}$ (Fig. 13) se produce las conexiones desde Arganzuela a Carabanchel y Usera. Ambos puentes son de uso peatonal, y también para ciclistas el de Perrault desde cuyo interior se puede descender al histórico Parque de la Arganzuela.

Sigue el Puente de Praga, inaugurado en 1952, para el tráfico y uso peatonal, los modernos Puentes Gemelos (Invernadero y Matadero), ambos abovedados y con decoración de mosaicos de vidrio reciclado de Daniel Canogar; un ejemplo de colaboración de los artistas plásticos y arquitectos e ingenieros. Cada

\footnotetext{
${ }^{55}$ Dominique Perrault, arquitecto. Escultura-puente, 274 mts. Forma cónica, malla metálica.
} 
puente gemelo se dirige o al Invernadero (Fig. 14) o al Centro de Creación Contemporánea y recinto del Matadero, escenario de múltiples actividades de ocio y cultura. Un proyecto de las ideas generadas sobre su historia puesta en boca de los habitantes de la zona es Matadero Memoria Aural56 "Proyecto sonoro de aproximación a la historia y recuerdos del matadero municipal de Madrid y su entorno más inmediato en el barrio de Arganzuela".

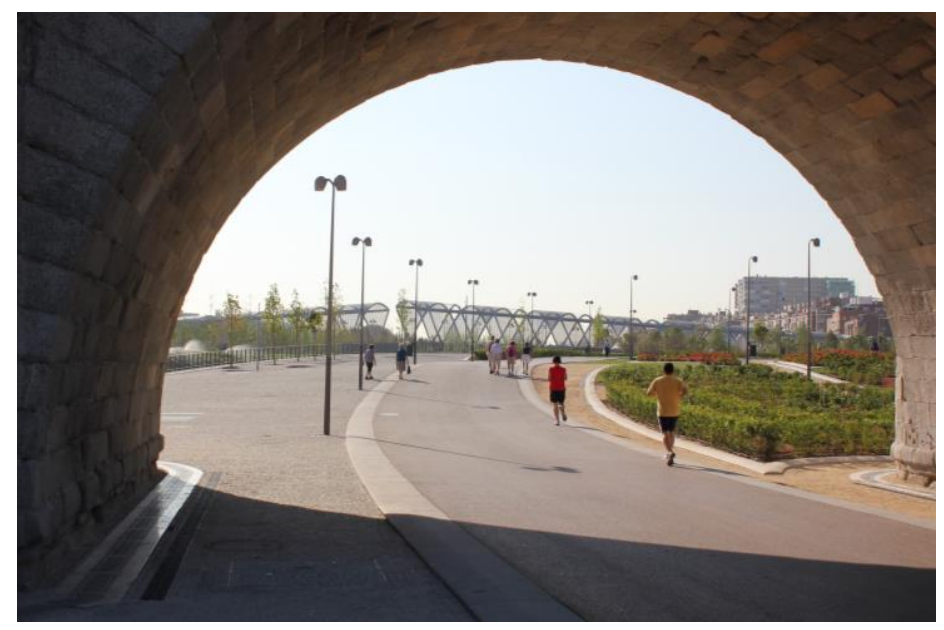

Fig. 13. Puente de Perraut desde el Puente de Toledo, Madrid Río, 2013. Fuente: M.D. Arroyo

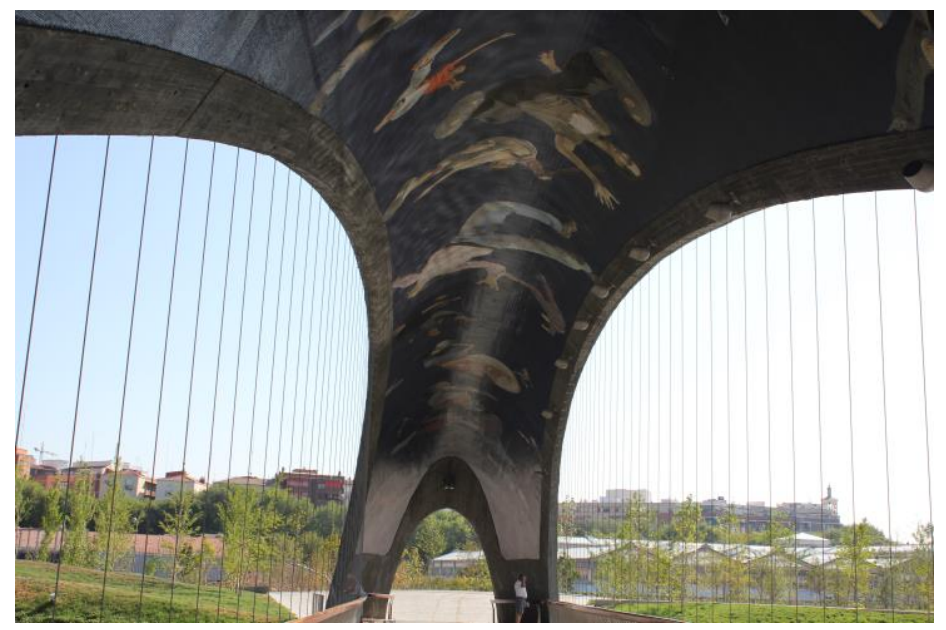

Fig. 14. Puente del Invernadero con decoración de Daniel Canogar, Madrid Río, 2013. Fuente: M.D. Arroyo

${ }^{56}$ http://mma.soundreaders.org/ 
Finalmente, el Puente de la Princesa y una pasarela dan acceso al Parque Lineal del Manzanares ${ }^{57}$ (Usera), que en su conjunto se extiende desde el nudo Sur de la M-30 hasta Rivas Vaciamadrid. Su primer tramo (fig. 15) se finalizó a mediados del 2003 por el taller de Ricardo Bofill. Entre otros, consta de distintos espacios como: Plaza Verde, Paseo de los Sentidos, Pérgola, La Atalaya - donde se encuentra la escultura Ariadna o La Dama del Manzanares de Manolo Valdés-, Área de los Deportes, La Pradera, Parque del Belvedere. Finalmente, desde la Montaña Forestal o el Cerro Coyote se distingue la Caja Mágica (Complejo Deportivo Polivalente) proyecto adjudicado a Dominique Perrault en 2002.

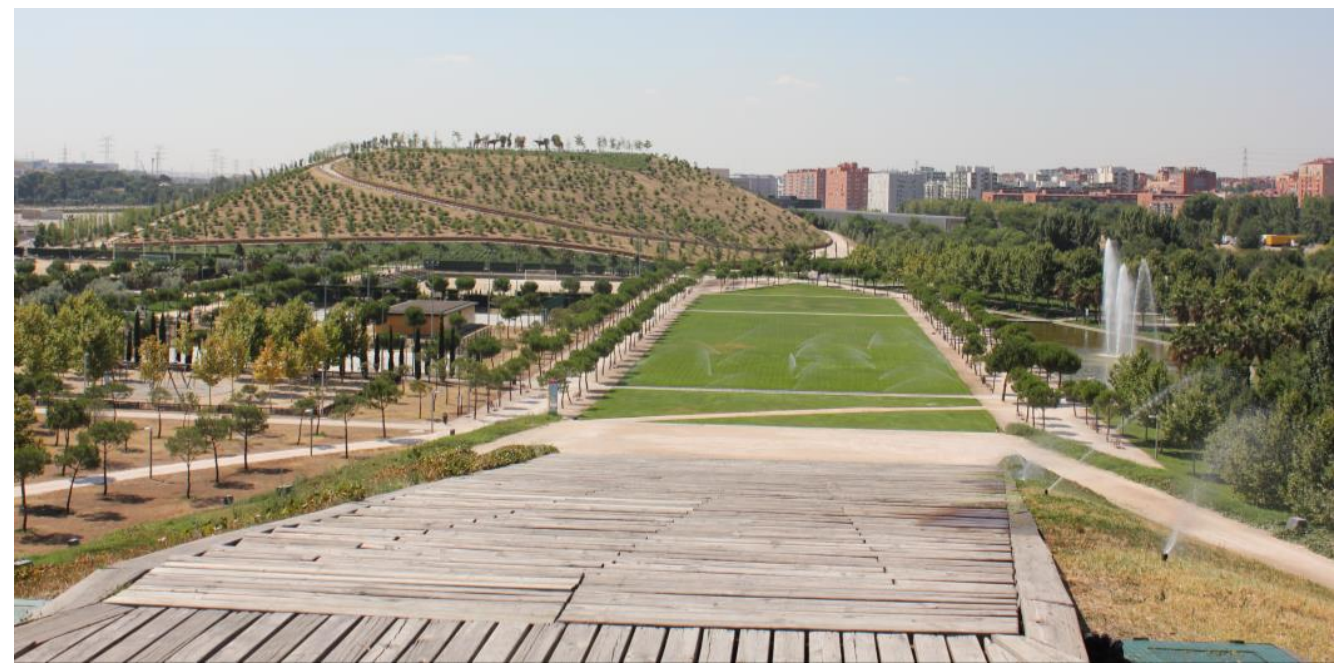

Fig. 15 - Parque Lineal del Manzanares, Madrid Río, 2013. Fuente: M.D. Arroyo

Considerando lo estudiado en este recorrido sintético que enlaza el eje Castellana-Prado-Recoletos al Madrid Río, se insiste en ese carácter de ciudad dinámica, cambiante, que se transforma y adapta a las necesidades de cada época. Recupera espacios e inutiliza otros. Pero jamás la ciudad es ni será estática. La frase "hacer ciudad" se ha puesto de moda, y todos participamos, cada habitante, cada ciudadano, cada público, cada turista. Se habla de ciudad participativa, intervenida, conceptual, funcional, adaptada a las necesidades e ideologías de cada época. Un "Madrid sin barreras", que conecta ba-

$57 \mathrm{http}: / / w w w \cdot p a r q u e l i n e a l . e s /$ introduccion/ 
rrios, culturas experiencias, que invita a ser recorrida a pie, a jugar, a ejercitar deporte, y a disfrutar de su cultura mediante el apoyo de mapas, placas informativas, folletos en la web. Pero esas transformaciones exigen adaptación, y como manifiesta tan sinceramente Jacques Herzog en entrevista para Babelia desde su estudio de Basilea: “(...) intentamos adaptarnos a un mundo en mutación (...) Este cambio dramático (...), pasa por encima de nosotros como una ola (...), y no queremos ignorarlo, pero tampoco que nos arrastre". (Hernández-Galiano, 2003:28).

\section{Bibliografía.}

ARroyo FERnÁndeZ, M.D. (1990). “El Centro de Arte Reina Sofía” en Guía de Arte 88'89 anuario. Barcelona: ART-85, S.A. Vol.7, pp.153-157.

_ (2011). “Entorno urbano y escultura pública: el monumento a Agustín Argüelles. Un caso de traslados, restituciones, desvirtualizaciones". Actas I Jornadas Internacionales de Investigación Arte y Ciudad, 24 y 25 de noviembre de 2011. Madrid: Grupo de Investigación Arte, Arquitectura y Comunicación en la Ciudad Contemporánea. Universidad Complutense de Madrid, pp. 275-287.

_ (2012, XI). “Diálogo de esculturas: Estética, metáfora y comunicación de la escultura monumental de la Plaza de la Moncloa de Madrid". Actas del II Congreso Internacional de Ciudades Creativas, 26 al 28 de octubre de 2011. Vol. 1. Madrid: Icono14 Asociación Científica de Comunicación, pp. 229 - 238.

_ $(2012$, X). “Arte en la calle: evolución del concurso internacional Madrid Abierto en el periodo 2004-2007", en Arte y Ciudad, Revista de Investigación. № 2, pp.87-98.

_ (2012, X). "Museo de Arte Público versus Madrid Abierto", en Arte y Ciudad, Revista de Investigación, № 2, pp.139-154.

_ (2015). “Configuración de la nueva imagen urbana y artística de Madrid Río como eje de conexión y regeneración cultural de los barrios colindantes" en CABAÑAs BRAVO, M.; Rincón GARCia, W. (Eds.), El Arte y la Recuperación del pasado reciente. Madrid: Consejo Superior de Investigaciones Científicas.

BitACORAS.COM (2013, 14-V). “Torres de Colón, uno de los edificios más singulares de Madrid“, $A B C$, Tecnología.

http://www.abc.es/tecnologia/redes/20130514/abci-edificios-singularesmadrid-201305140922.htmls 
Brown, A. (2014, 20-IV): “El Monumento a Calvo Sotelo, el último homenaje al "Protomartír" (1960)", en 1960-1969 (El desarrollismo económico), Distrito de Chamartín.

https://elmadriddefranco.wordpress.com/2014/04/20/monumento-a-calvosotelo-1960/

CASAS LÓPEZ-AMOR, L. (2005). Rehabilitación 4º depósito del Canal de Isabel II en la Plaza de Castilla de Madrid. Madrid: Fundación ACS.

FARINA (2008, 20-XI). “Espacios malditos: Madrid, Plaza de Castilla”. Disponible en http://elblogdefarina.blogspot.com.es/2008/11/espacios-malditosmadrid-plaza-de.html

FERNÁNDEZ DELGADO, J. [et al.] (1982). La memoria impuesta: Estudio y catálogo de los monumentos conmemorativos de Madrid (1939-1980). Madrid: Ayuntamiento de Madrid, Delegación de Cultura.

Fotonoticia (2010, 6-XI). El País, Madrid. Disponible en http://elpais.com/diario/2010/11/26/madrid/1290774267_850215.html

GARCÍA, Ángeles (2008, 3-VII). “La 'Noche' y el 'Día' de Antonio López llegan a Atocha. Las dos gigantescas esculturas recibirán a los viajeros del AVE". El País, Madrid.

http://elpais.com/diario/2008/07/03/madrid/1215084264_850215.html

HemerotecA ABC (2008, 20-II). “Las esculturas de Igor Mitoraj llegan al Paseo del Prado". $A B C$, Madrid. Disponible en http://www.abc.es/hemeroteca/historico-20-02-2008/abc/Madrid/lasesculturas-de-igor-mitoraj-llegan-al-paseo-del-prado_1641658875817.html

HemerotecA ABC $(2001,10-V)$ "De antigua Central Eléctrica a centro cultural". $A B C, \quad$ Madrid. http://www.abc.es/hemeroteca/historico-10-052001/abc/Madrid/de-antigua-central-electrica-a-centro-cultural_30063.html

Hernández-Galiano, L. (2003, 8-II). “Caja de sorpresas”, El País, Babelia, Madrid, p. 28.

PLA, Carlos y Abogados (1991, 26-IX). “CARTAS AL DIRECTOR: Monumento a Calvo Sotelo". El País, Madrid. Disponible en http://elpais.com/diario/1991/09/26/opinion/685836002_850215.html

Rubio PAMPLONA, Jesús (2008, 4 -V) "Juan Carrete Parrondo experto en arte". "Hoy hablamos, más que de artistas, de activistas". Diario de Navarra. 
http://www.diariodenavarra.es/20080504/culturaysociedad/hoy-hablamos-artistasactivistas.html?not=2008050402555737\&idnot $=2008050402555737 \&$ dia

$=20080504 \&$ seccion $=$ culturaysociedad $\&$ seccion $2=\&$ chnl $=40$

SAlVAdOR PRIETO, M. del S. (1990). Escultura monumental en Madrid: calles, plazas y jardines públicos (1875-1936). Madrid: Editorial Alpuerto.

SANZ CASILLAS, J. (2014, 25-I). “El «Obelisco de Calatrava», un lustro de decepción". ABC, Madrid. http://www.abc.es/madrid/20140125/abci-obeliscocalatrava-lustro-decepcion-2014 Madrid / URBANISMO

SUDJIC, Deyan (2007). La arquitectura del poder: cómo los ricos y poderosos dan forma al mundo. Barcelona: Ariel.

ZabalbeAscoA, A. (2008, 15-III). “El Problema del paisaje actual es la fragmentación”, El País, Babelia, Madrid, p. 24. 